\title{
JUSTICIA POSTRANSICIONAL EN GUATEMALA: EL ROL DE LOS JUECES EN LA PROTECCIÓN DE DERECHOS HUMANOS*
}

\author{
"Post-Transitional Justice in Guatemala: The Role of the Judges in \\ Human Rights Protection"
}

\section{MARTHA LILIANA GUTIÉRREZ}

Universidad Jorge Tadeo Lozano de Bogotá

\begin{abstract}
RESUMEN
Partiendo de la base de que más allá de las decisiones adoptadas en un primer momento por las élites políticas, el poder judicial puede influir el proceso transicional, el propósito de este trabajo es indagar cuál ha sido la respuesta de las Altas Cortes guatemaltecas frente a las graves violaciones a los derechos humanos perpetradas durante el conflicto armado. Para ello se hará un análisis cualitativo comparativo de providencias emitidas por Altas Cortes, examinando cómo han fallado en los casos que han llegado hasta ellas, las posibles explicaciones de sus decisiones, así como el impacto potencial de dichas providencias frente al conjunto de casos judicializados y las violaciones reportadas en los informes de las Comisiones de la Verdad.
\end{abstract}

Palabras clave: Justicia postransicional, derechos humanos, Altas Cortes, Guatemala.

\begin{abstract}
Assuming that, beyond the decisions taken by political elites, the Judiciary can influence the transitional process, this work aims to explore and explain the role of Guatemalan High Courts in the prosecution of Human Rights violations and crimes committed during the armed conflict. In order to analyze this issue, we carry out a qualitative comparative analysis on decisions from High Courts in Guatemala. We examine how these institutions have ruled the cases that have come to them, the possible causes of their decisions and the potential impact of those verdicts to the whole of trials and violations reported by different Truth Commissions.
\end{abstract}

Key words: Post-transitional justice, human rights, High Courts, Guatemala.

* Agradezco a todos aquellos que con sus comentarios contribuyeron a mejorar este trabajo, especialmente a Elena Martínez Barahona y Sebastián Linares (Universidad de Salamanca), así como las importantes sugerencias del revisor anónimo de la Revista de Ciencia Política. 


\section{INTRODUCCIÓN}

Además de la influencia del poder judicial en el período potransicional, la investigación asume que las decisiones judiciales dependen de aspectos que están más allá de la ley y que inciden en los jueces, que como los demás actores políticos actúan estratégicamente previendo las consecuencias de sus fallos. Todo esto con fundamento en literatura sobre judicial politics y principalmente con apoyo en Skaar (2011), en cuanto a variables potencialmente relevantes para la criminalización de violaciones de los derechos humanos, así como en Martínez Barahona (2009) y su estudio respecto del rol político del poder judicial en Centroamérica.

La primera parte del trabajo se ocupa de la discusión teórica relativa a los temas de estudio así como del diseño de investigación; en la segunda se describen los casos, indagando si se trata de decisiones de protección o desprotección judicial de derechos humanos, para pasar en la tercera parte al análisis explicativo y finalizar con las conclusiones.

\section{DISCUSIÓN TEÓRICA Y DISEÑO DE INVESTIGACIÓN}

\section{Poder Judicial y Justicia postransicional}

El tema de las transiciones a la democracia ha sido abordado principalmente desde las elites políticas, de forma tal que se ha señalado que para su estudio "la variable clave es la fuerza relativa de los grupos prorreforma que surgen del antiguo régimen, los grupos moderados de oposición y los grupos intransigentes de ambos lados" (Barahona de Brito et al., 2002: 44). Los estudiosos han encontrado que en el primer momento de la transición es el pulso entre dichos grupos el que determinará qué tipo de medidas se adoptan, y si ellas incluyen los juicios a los represores ( $\mathrm{O}^{\prime}$ Donnell y Schmitter, 1986; Karl, 1990).

Más allá de las decisiones adoptadas al inicio, el poder judicial, con sus providencias sobre criminalización de violaciones a los derechos humanos y defensa de los mismos, o la ausencia de ellas, influye el proceso. ${ }^{1}$ Es así como algunos países han adelantado juicios a pesar de la existencia de leyes de amnistía y en ocasiones los tribunales han invocado tratados e interpretaciones de organismos internacionales para criminalizar en el ámbito nacional las violaciones del pasado (Roht-Arriaza, 2002). A medida que adquieren un rol más relevante, algunos tribunales asumen un papel más activo en la persecución de los violadores de derechos humanos, llegando a convertirse en actores claves del proceso postransicional (Skaar, 2011; Collins, 2010).

En el presente trabajo se sigue la conceptualización de Skaar (2011) sobre transición y justicia transicional. La transición es el paso de una sociedad menos democrática

1 Barahona de Brito advierte que “[a] veces lo que parece terminado está todavía por empezar y, en ocasiones, ocurre que las políticas de verdad y justicia que se descartaron en los primeros años de la transición se convierten en plausibles muchos años después" (Barahona de Brito et al., 2002: 438). 
a una más democrática, mientras la justicia transicional está compuesta por los mecanismos formales o informales dirigidos a conjurar las violaciones del pasado, que incluyen juicios, comisiones de la verdad, amnistías, purgas, programas de reparación, entre otros.

Por su parte, la justicia postransicional es definida por Skaar como la judicialización de las graves violaciones a los derechos humanos cometidas durante el régimen militar, ya sea mediante causas penales o juicios civiles, llevados a los tribunales por lo menos un ciclo electoral después de la transición a la democracia (Skaar, 2011: 29). Es decir, que Skaar centra su definición solo en el aspecto judicial de la persecución de graves violaciones a los derechos humanos, a diferencia de Collins (2010), quien usa el término en un sentido más amplio, incluyendo otros mecanismos de la justicia transicional, en un tiempo no definido. Aquí nos ocupamos como Skaar solo del aspecto judicial, pero como Collins no limitamos los juicios a los más tardíos.

Además de constatar que algunos jueces son más activos que otros en la protección de derechos humanos, es factible preguntarse por qué ello es así. Booth Walling y Sikkink (2008) demostraron que en materia de juicios por violaciones a los derechos humanos el nivel interno y el internacional suelen interactuar, como quiera que las limitaciones de las justicias nacionales llevan a las víctimas a acudir a tribunales extranjeros. A su vez, el éxito de los juicios internacionales puede generar apertura de juicios internos.

Estas aportaciones son recogidas por Skaar (2011), que indaga cuándo y en qué condiciones es posible que se responsabilice a militares de las violaciones de derechos humanos cometidas durante los regímenes autoritarios, frente a lo cual apunta que las presiones que más inciden son las de los militares en contra de los juicios y las provenientes del ámbito interno e internacional, reclamando justicia y respeto a los derechos humanos.

Estos trabajos se enmarcan en un campo más amplio que analiza los jueces como actores políticos. Desde la ciencia política ha habido diversas aproximaciones para el estudio de los tribunales: el modelo legal, el modelo institucional, el modelo actitudinal y el modelo del comportamiento estratégico de los jueces (Knight y Epstein, 1996; Epstein, Knight y Martin, 2001; Helmke y Sanders, 2006; Sommer y Sekercioglu, 2007). Más recientemente se ha desarrollado la "teoría del balance táctico" (Kapiszewski, 2009) enmarcada en el modelo del comportamiento estratégico. ${ }^{2}$

Los estudiosos de judicial politics en muchos casos parten del supuesto de que la intervención judicial es positiva para la democracia, sin embargo, en un plano más general

\footnotetext{
Mientras el modelo legal confía en la fuerza de la ley para constreñir el comportamiento de los jueces, el modelo institucional pone el énfasis en cómo la arquitectura institucional influye sus actuaciones, el modelo actitudinal en sus preferencias y el modelo del comportamiento estratégico, en la racionalidad de los operadores judiciales al momento de tomar decisiones y, por lo tanto, en las maniobras que despliegan para maximizar sus beneficios. Finalmente, la "teoría del balance táctico" -desarrollada para casos políticamente controversialesparte de la base de que no existe un único factor capaz de explicar el comportamiento judicial. Según esta teoría, en las decisiones políticamente controversiales confluyen distintos factores respecto de los cuales los jueces hacen un balance táctico, para cada caso (Kapiszewski, 2009).
} 
el papel de los jueces encuentra contradictores. Los críticos sostienen que la legitimidad democrática no radica en los jueces (Dahl, 2000; Linares, 2008; Walzer, 2010), a lo que se suma que al tratarse de órganos no representativos no pueden ser objeto de control por parte del electorado. Por otro lado denuncian riesgos de politización de la justicia (Domingo, 2004: Martínez Barahona, 2009) o de su uso como arma política (Maravall, 2003 y 2008; Walzer, 2010).

El argumento principal de quienes defienden la participación activa de los jueces se sustenta sobre la supremacía de la Constitución y la necesidad de su protección aun en contra de la voluntad de las mayorías políticas y el propio Estado (Courtis, 2005: 69, 70). Kapiszewski y Taylor (2008) resaltan que los vínculos entre poder judicial y democracia por lo general no han sido estudiados empíricamente, lo que hace muy difícil llevar a un plano superior este debate.

En cualquier caso, luego de las transiciones a la democracia la reforma judicial se ha encaminado a reforzar la independencia del sector incrementando las posibilidades de accountability y sanción a las autoridades públicas. Es en este punto en el que se ubica este trabajo, que se adhiere a quienes reconocen como uno de los pilares del régimen democrático el Estado de derecho y el respeto de los derechos humanos, ámbitos donde los jueces pueden llegar a desempeñar un papel central. ${ }^{3}$

Creemos pues que los jueces no son aplicadores ciegos de las normas y que al interpretar la ley actúan como actores estratégicos, más aún en casos políticamente controversiales, donde para resolver se espera que sopesen los efectos de sus decisiones y las consecuencias que de ellas se deriven para sí mismos. Sin embargo, su comportamiento no está conducido siempre por un mismo factor sino por varios, en diversas combinaciones, con un importante peso de aspectos institucionales y actitudinales.

\section{Diseño de investigación}

Para indagar por qué en unos casos las altas Cortes protegen los derechos humanos y en otros no, en asuntos relacionados con períodos represivos, autoritarios o de conflicto armado, se analizarán decisiones que implican protección -o no- de derechos humanos. ${ }^{4}$

3 Si se entiende la democracia como un concepto que va más allá del régimen y en consecuencia, además de elecciones limpias y competitivas presupone ciertas libertades y garantías fundamentales (O`Donnell, 2007), resulta manifiesta la afectación que produce el hecho de que desde la política oficial se garantice la impunidad frente a graves afectaciones a los derechos humanos. Además, su reconocimiento y protección judicial no puede ser visto como limitación a la democracia, por provenir de órganos contramayoritarios, sino como garantía de la misma (Uprimny, 2007).

4 Por decisiones se entienden aquellas providencias adoptadas por los jueces, donde resuelven con carácter imperativo el asunto puesto en su conocimiento. Pude tratarse de sentencias proferidas en procesos ordinarios, trámites de amparo, fallos de constitucionalidad, resoluciones u otras providencias análogas. Lo que interesa para efectos del presente trabajo es que se ocupen de temas relacionados con el proceso transicional y la defensa de los derechos humanos. 
Aun cuando el número de casos que han llegado a las altas Cortes en Centroamérica es todavía bajo, resulta pertinente analizarlos. Se ha optado por empezar por Guatemala, donde un grupo de decisiones de las altas Cortes permite estudiar el rol del poder judicial en la defensa de los derechos humanos, durante y después de la transición.

Se estudian fallos de la Corte de Constitucionalidad (CC) y la Cámara Penal de la Corte Suprema de Justicia (CSJ), que son los órganos que conocen en última instancia de los procesos y acciones en materia penal y constitucional, y son, por lo tanto, órganos de cierre en estos asuntos. Las decisiones seleccionadas corresponden a aquellas proferidas por las altas Cortes de Guatemala en casos conocidos como paradigmáticos en diferentes estudios e informes. ${ }^{5}$

Se trata de una comparación al interior de un país, partiendo del análisis de providencias judiciales, algunas de las cuales se encuentran en la página web de la Corte de Constitucionalidad y en las páginas web de ONG. Otras decisiones, que no estaban a disposición en la red, fueron obtenidas con ayuda de informantes claves. ${ }^{6}$

Si bien las decisiones ofrecen dificultades para la comparación, se analizan teniendo como hilo conductor la protección de derechos humanos. Se apela a un análisis comparativo cualitativo (QCA), buscando verificar o descartar hipótesis a través de la comparación de casos positivos y negativos, que permitan observar cambios en la variable dependiente.

Conscientes del escaso número de casos que han llegado a las altas Cortes de Guatemala y de la poca atención que ha recibido el tema en Centroamérica, se advierte que no es objeto de este estudio indagar el porqué de dicho rezago, sino analizar la respuesta de las Cortes en los asuntos que han llegado hasta ellas.

\section{La protección de derechos humanos por las altas Cortes: variable dependiente}

Cuando hablamos de protección judicial de derechos humanos nos estamos refiriendo a la adopción de decisiones donde los jueces castigan violaciones a los mismos, así como a la adopción de otras decisiones que inciden directamente en su protección, al ampliar las posibilidades de criminalización. ${ }^{7}$

Limitadas a aquellas a las que se ha podido tener acceso.

Entre los que hago mención especial a Álvaro Castellanos Howell y Almudena Bernabéu con quienes tuve entrevistas durante los meses de diciembre de 2010 a marzo de 2011.

Uprimny y Guzmán (2007) señalan cuatro grandes grupos de factores que contribuyen a que se extienda la impunidad: normativos, político institucionales, sociales y técnicos-organizacionales, y añaden que los mejores ejemplos del primer grupo, "conformado por un conjunto de dispositivos, mecanismos y figuras jurídicas que se convierten en factores de impunidad" son "las leyes de amnistía, la prescripción, el non bis in idem y la ausencia de tipificación de conductas, así como el uso del fuero militar para evadir el juzgamiento por parte de tribunales más independientes" (Uprimny y Guzmán, 2007: 3). Como buenas prácticas que contribuyen a la lucha contra la impunidad, incluyen la anulación legislativa y judicial de leyes de punto final, la reinterpretación judicial de amnistías, la limitación jurisprudencial y por tratados del non bis in idem y la restricción del fuero militar, tanto desde el legislativo como desde el judicial, las que, desde la óptica de este trabajo, inciden en mayores posibilidades de criminalización. 
El Cuadro 1 refleja que la protección judicial, como la entendemos aquí, admite dos dimensiones:

Cuadro 1. Variable dependiente, dimensiones e indicadores

\begin{tabular}{|c|c|c|}
\hline Variable dependiente & Dimensiones & Indicadores \\
\hline \multirow{9}{*}{$\begin{array}{l}\text { Protección judicial de los } \\
\text { derechos humanos } \\
\text { (Altas Cortes) }\end{array}$} & (1) & Impone condena criminal \\
\hline & \multirow{3}{*}{$\begin{array}{l}\text { Criminaliza } \\
\text { violaciones a los } \\
\text { DD.HH. }\end{array}$} & Confirma condena criminal \\
\hline & & Revoca absolución y condena \\
\hline & & Restringe el fuero militar \\
\hline & \multirow{5}{*}{$\begin{array}{l}\text { (2) } \\
\text { Amplía } \\
\text { posibilidades de } \\
\text { criminalización de } \\
\text { violaciones a los } \\
\text { DD.HH. }\end{array}$} & Restringe aplicación de amnistías \\
\hline & & Restringe posibilidades de prescripción \\
\hline & & $\begin{array}{l}\text { Restringe el principio que prohíbe ser juzgado } \\
\text { dos veces por los mismos hechos }\end{array}$ \\
\hline & & $\begin{array}{l}\text { Ordena investigación criminal contra otros } \\
\text { involucrados }\end{array}$ \\
\hline & & $\begin{array}{l}\text { Reconoce carácter de crimen más grave, de } \\
\text { trascendencia para la comunidad internacional }\end{array}$ \\
\hline
\end{tabular}

Fuente: Elaboración propia

Los indicadores pueden concurrir, pero con que se presente uno solo de ellos se entiende que la decisión implica protección judicial de los derechos humanos. En caso de que se presente el indicador, pero en sentido opuesto, podremos hablar de casos que restringen las posibilidades de criminalización y, por lo tanto, de desprotección judicial de los derechos humanos.

\section{Buscando una explicación: variables independientes e hipótesis}

Más allá de indagar por la protección judicial de los derechos humanos en las altas Cortes guatemaltecas, es del caso intentar una explicación. Skaar (2011: 37) se pregunta qué incide, además de la independencia judicial, en una mayor propensión de los jueces a conocer de estos casos, y en busca de desentrañar los cambios de comportamiento judicial centra su atención en las interacciones entre los protagonistas de los juicios: los jueces que deciden, los militares o acusados y las víctimas, sujetos en torno a los que elaboramos nuestras variables independientes. Asimismo se tiene en cuenta la influencia de decisiones de organismos judiciales de carácter internacional.

Se insiste, en todo caso, que se trata de una comparación al interior de un país, por ello las hipótesis que se plantean a continuación se suscriben al contexto guatemalteco y aunque se espera testarlas más adelante en otros contextos -como el salvadoreño- no tienen en este momento pretensión de universalidad. 


\section{Presiones proimpunidad $(x 1)$ :}

Durante las transiciones los militares pudieron establecer "condicionantes no democráticos", también llamados "enclaves autoritarios", como la exclusión de líderes políticos, presiones para impedir procesos constituyentes o determinadas reformas que incidieran en la competencia electoral, así como presiones para "contrarrestar las políticas de derechos humanos" (Alcántara y Freidenberg, 2006: 95).

Rouquié (1997: 335) sostiene que la desaparición del gobierno militar no garantiza la extinción de la influencia política de las fuerzas militares, mientras Skaar (2011) señala que cuanto menor es la amenaza que representan los militares, hay mayores posibilidades de que se les juzgue, lo que explicaría que los juicios se lleven a cabo pasado un tiempo de la transición. Bajo esta misma lógica es del caso esperar que se presente más fácilmente la judicialización de bajos rangos que de militares o políticos influyentes.

Nuestra hipótesis es que cuando hay políticos o altos mandos militares -que formaron parte de los regímenes autoritarios- involucrados en el caso, como presuntos perpetradores de violaciones a los derechos humanos, la Corte fallará en contra de tales derechos.

\section{Demandas de justicia - "social accountability"8 (x2):}

Skaar (2011: 38) señala que las demandas sostenidas de justicia por parte de la sociedad civil influyen la posibilidad de realización de los juicios, mientras Collins (2006) defiende la importancia de los actores internos en el cambio jurídico nacional y una mayor accountability social a través de causas penales y civiles en el Cono Sur, incluso por encima de las presiones internacionales en defensa de los derechos humanos.

En este orden de ideas, nuestra Hipótesis es que cuando en el proceso intervienen terceros individuales u ONG de carácter doméstico, reclamando la protección de derechos humanos, las altas Cortes adoptarán decisiones en defensa de ellos.

\section{Trayectoria politica de los jueces ( $x 3)$ :}

Al estudiar el rol político de las altas Cortes en Guatemala, Martínez Barahona (2009: 117) deja claro que la Corte de Constitucionalidad muestra niveles más bajos de independencia que la Corte Suprema de Justicia y concluye que la gran diferencia

\footnotetext{
Luego de que O'Donnell distinguiera entre accountability vertical y horizontal, Peruzzotti y Smulovitz distinguieron a su vez, en el plano de la vertical, la accountability social de la electoral: "La accountability social es un mecanismo de control vertical, no electoral, de las autoridades políticas basado en las acciones de un amplio espectro de asociaciones y movimientos ciudadanos, así como también en acciones mediáticas [...] La accountability social puede canalizarse tanto por vías institucionales y como no institucionales. Mientras que las acciones legales o los reclamos ante los organismos de supervisión son ejemplos de las primeras, las movilizaciones sociales y las denuncias mediáticas, orientadas usualmente a imponer sanciones simbólicas, son representativas de las segundas" (Peruzzotti y Smulovitz, 2002: 32)
} 
entre una y otra radica en su nombramiento, lo que a su vez incide en los perfiles y trayectorias profesionales de los magistrados (Martínez Barahona, 2009).9

Los hallazgos para el caso de Guatemala muestran que la designación de magistrados es un mecanismo para cooptar a las Cortes y subordinarlas al poder político (Martínez Barahona, 2009). Es por ello que nos proponemos estudiar sus perfiles y trayectorias profesionales, con miras a determinar si esto incide en el sentido de las decisiones respecto de protección a los derechos humanos.

Nuestra hipótesis es que cuando las sentencias son suscritas por magistrados con mayor tradición en el sector judicial y que no tienen familiares en política, las altas Cortes adoptarán decisiones en defensa de los derechos humanos, mientras las sentencias proferidas por magistrados con mayor tradición política ${ }^{10}$ tenderán a una menor protección de los mismos. ${ }^{11}$

Sería interesante poder incluir la ideología política de los jueces así como la fuerza política que mayor incidencia ha tenido en su nombramiento y contrastarlas con aquella a la que podrían beneficiar las decisiones analizadas, sin embargo, por ahora no se cuenta con datos que permitan medir tales supuestos. A falta de tal información, se parte de la base de que la vinculación política resta independencia a los juzgadores, que por tanto tenderán a la desprotección judicial de los derechos humanos. ${ }^{12}$

9 Más controlados por políticos en el caso de la Corte de Constitucionalidad (Martínez Barahona, 2009: 230) y más relacionados con el sector judicial en el caso de la Corte Suprema, lo que se evidencia en mayores porcentajes de magistrados que han trabajado en el poder judicial y/o tienen familiares que han trabajado en él, y menores porcentajes de familiares en política (Martínez Barahona, 2009: 232-233).

10 Siguiendo la línea marcada por Martínez Barahona (2009) aquí se entiende que un magistrado tiene mayor tradición judicial cuando se ha dedicado bien a la judicatura, la docencia o el litigio. Por el contrario, tendrá mayor tradición política cuando ha desempeñado cargos de nombramiento político o tiene familiares en política.

11 Como se trata de decisiones aprobadas de forma conjunta sin que sea posible identificar en cada caso el parecer de cada uno, se da por cierta su aprobación salvo que exista constancia de lo contrario (voto disidente o razonado) y con que uno solo tenga trayectoria política o familiares en política, se entenderá que está presente el indicador. Es verdad que esta decisión puede hacer que los resultados que arroje el estudio sean sobredeterminados para esta variable, pero la imposibilidad de individualizar el sentido de una decisión colegiada obliga a hacerlo así.

12 Toda vez que se entiende que, haciendo a un lado la ideología política, los jueces más independientes tienden a respetar estándares internacionales de protección de derechos humanos en mayor medida que aquellos menos independientes. Esto nos lleva a la discusión planteada en la teoría del derecho contemporánea sobre la aplicación del derecho en casos concretos, donde se encuentran diversas posturas en cuanto a la neutralidad de los jueces o la falta de ella. Hay quienes defienden la coherencia interna del derecho y por lo tanto la incapacidad del juez de ser creador del mismo (Dworkin, 1977), quienes señalan que en algunos casos -difíciles- el derecho es indeterminado y los jueces tienen discrecionalidad para decidir (Hart, 1992) y aquellos de postura más crítica para quienes los jueces no solo crean derecho sino que lo hacen guiados por motivaciones ideológicas, que se disfrazan de técnicas (Kennedy, 1997). Este trabajo coincide con la postura intermedia y es por ello que se espera que en la gran mayoría de los casos los jueces más independientes además de seguir las reglas establecidas en el ordenamiento interno se guíen por los principios que señala el mismo ordenamiento, así como por aquellos desarrollados en el ámbito internacional que tienden a la protección de los derechos humanos, sin que sea preciso que dichos jueces respondan a determinada ideología. Nos alejamos pues de aquellos que señalan el carácter completo del derecho, pero también de los que señalan que las decisiones judiciales en todos los casos están exclusivamente motivadas por aspectos internos al juez y esconden intereses ocultos. Pasando de la teoría del derecho a la ciencia política, se reitera que se considera que los jueces actúan estratégicamente 


\section{Decisiones previas de Cortes internacionales $(x 4)$ :}

La influencia internacional es tenida en cuenta tanto cuando se estudia a los jueces (Martínez Barahona, 2009) como cuando se estudian la justicia transicional y la defensa de los derechos humanos (Keck y Sikkink, 1998; Booth Walling y Sikkink, 2008: 22). Skaar (2011) incluye las presiones internacionales por el respeto a los derechos humanos como condición favorable para que se juzgue a los militares que hicieron parte de regímenes autoritarios.

Nuestra hipótesis es que cuando hay decisiones adoptadas por Cortes internacionales -a cuya jurisdicción está sometida Guatemala- que se han pronunciado sobre el mismo tema o asunto en defensa de los derechos humanos, las Cortes nacionales adoptarán providencias en el mismo sentido.

El Cuadro 2 reúne cada una de las variables independientes, con sus indicadores e hipótesis:

Cuadro 2. Variables independientes, indicadores e hipótesis

\begin{tabular}{|c|c|c|}
\hline $\begin{array}{c}\text { Variables } \\
\text { independientes }\end{array}$ & Indicadores & Hipótesis \\
\hline $\begin{array}{l}\text { Presiones } \\
\text { proimpunidad }\left(\mathrm{x}^{1}\right)\end{array}$ & $\begin{array}{l}\text { Altos mandos militares } \\
\text { o políticos que formaron } \\
\text { parte de los regímenes } \\
\text { autoritarios involucrados } \\
\text { en el caso }\end{array}$ & $\begin{array}{l}\text { Cuando hay políticos o altos mandos militares } \\
\text { involucrados en el caso, como presuntos } \\
\text { perpetradores de violaciones a los derechos } \\
\text { humanos, la Corte fallará en contra de tales } \\
\text { derechos. }\end{array}$ \\
\hline $\begin{array}{l}\text { Demandas de } \\
\text { justicia por la } \\
\text { sociedad civil social } \\
\text { accountability }\left(\mathrm{x}^{2}\right)\end{array}$ & $\begin{array}{l}\text { Ciudadanos o ONG } \\
\text { locales que se vinculan al } \\
\text { proceso para impulsarlo }\end{array}$ & $\begin{array}{l}\text { Cuando en el proceso intervienen terceros } \\
\text { individuales u ONG, reclamando la protección } \\
\text { de derechos humanos, las altas Cortes } \\
\text { adoptarán decisiones en defensa de ellos. }\end{array}$ \\
\hline $\begin{array}{l}\text { Trayectoria política } \\
\text { de los jueces }\left(x^{3}\right)\end{array}$ & $\begin{array}{l}\text { Cargos anteriores en } \\
\text { política o familiares en } \\
\text { política }\end{array}$ & $\begin{array}{l}\text { Las sentencias proferidas por magistrados } \\
\text { con mayor tradición política o familiares en } \\
\text { política tenderán a una menor protección de } \\
\text { los derechos humanos. }\end{array}$ \\
\hline $\begin{array}{l}\text { Decisiones } \\
\text { previas de Cortes } \\
\text { internacionales }\left(x^{4}\right)\end{array}$ & $\begin{array}{l}\text { Decisiones previas de } \\
\text { Cortes internacionales } \\
\text { sobre el mismo tema o } \\
\text { asunto }\end{array}$ & $\begin{array}{l}\text { Cuando hay decisiones adoptadas por cortes } \\
\text { internacionales que se han pronunciado sobre } \\
\text { el mismo tema o asunto en defensa de los } \\
\text { derechos humanos, las altas Cortes adoptarán } \\
\text { decisiones en el mismo sentido. }\end{array}$ \\
\hline
\end{tabular}

Fuente: Elaboración propia 


\section{JUICIOS POR VIOLACIONES A LOS DERECHOS HUMANOS Y OTRAS DECISIONES RELACIONADAS CON EL PROCESO TRANSICIONAL}

La diferencia abismal entre los casos de violaciones de derechos humanos -de los que dan cuenta los informes de la Comisión de Esclarecimiento Histórico y el Proyecto de Recuperación de la Memoria Histórica- y los casos judicializados, se resume en el Cuadro 3:

Cuadro 3. Violaciones a los DD.HH. y procesos criminales

\begin{tabular}{ll}
\hline Violaciones a los derechos humanos & $\begin{array}{l}\text { Más de } 160.000 \text { ejecuciones extrajudiciales } \\
\text { Más de } 40.000 \text { desapariciones forzadas } \\
626 \text { masacres }\end{array}$ \\
\hline Casos judicializados & 1.749 \\
\hline
\end{tabular}

Fuente: Elaboración propia, a partir de datos extraídos de los informes de la CEH y REMHI, así como de Leonardo (2010).

El Cuadro 4 da cuenta del muy bajo número de casos que tienen condenas en firme:

Cuadro 4. Juicios criminales con sentencia en firme

\begin{tabular}{|c|c|c|}
\hline Caso & Condenados & Instancia \\
\hline Asesinato Myrna Mack & $\begin{array}{l}\text { Un especialista y un exjefe del Estado Mayor } \\
\text { Presidencial }\end{array}$ & CSJ \\
\hline Asesinato Monseñor Gerardi & Dos militares, un sacerdote y un exmiembro del EMP & CSJ \\
\hline Desaparición Forzada El Jute & $\begin{array}{l}\text { Un coronel del Ejército y cuatro comisionados } \\
\text { militares }\end{array}$ & Tribunal \\
\hline Desaparición Forzada Choatalum & Un comisionado militar & Tribunal \\
\hline Masacre de Tululché & Un comisionado militar & Tribunal \\
\hline Masacre Xamán & Un subteniente del ejército y 13 integrantes de su tropa & Tribunal \\
\hline
\end{tabular}

Fuente: Elaboración propia a partir de datos extraídos de fallos judiciales, reportes de prensa, Amnistía Internacional (2002), Leonardo (2010) y Pásara (2010).

Más allá de las condenas incluidas en el Cuadro $\mathrm{N}^{\circ} 4$, no todas adoptadas por las altas Cortes, en este apartado se analizan las decisiones detalladas en el Cuadro 5: 
Cuadro 5. Casos

\begin{tabular}{|c|c|c|c|c|c|}
\hline Caso & Corte & Fecha & Asunto & Tipo de decisión & Sentido de la decisión \\
\hline A & $\mathrm{CC}$ & 3-mar-97 & Fuero Militar & $\begin{array}{l}\text { Constitucionalidad } \\
\text { general }\end{array}$ & $\begin{array}{l}\text { Avala exclusión fuero militar } \\
\text { para delitos comunes }\end{array}$ \\
\hline B & CSJ & 9-feb-94 & \multirow{2}{*}{ Myrna Mack } & $\begin{array}{l}\text { Sentencia de casación } \\
\text { Autor material }\end{array}$ & $\begin{array}{l}\text { Casa parcialmente y dispone } \\
\text { continuar investigación contra } \\
\text { otros investigados }\end{array}$ \\
\hline $\mathrm{C}$ & CSJ & 14-ene-04 & & $\begin{array}{l}\text { Sentencia de casación } \\
\text { A. intelectuales }\end{array}$ & $\begin{array}{l}\text { Casa sentencia absolutoria y en } \\
\text { su lugar condena }\end{array}$ \\
\hline $\mathrm{D}$ & $\mathrm{CC}$ & 12-dic-07 & $\begin{array}{l}\text { Justicia } \\
\text { Universal }\end{array}$ & Apelación amparo & $\begin{array}{l}\text { Niega extradición reclamada } \\
\text { por la justicia española, Ríos } \\
\text { Montt y otros }\end{array}$ \\
\hline E & $\mathrm{CC}$ & 7-jul-09 & Choatalum & $\begin{array}{l}\text { Inconstitucionalidad } \\
\text { caso concreto }\end{array}$ & $\begin{array}{l}\text { Ratifica carácter permanente del } \\
\text { delito de desaparición forzada }\end{array}$ \\
\hline $\mathrm{F}$ & CSJ & 11-dic-09 & \multirow{4}{*}{$\begin{array}{l}\text { Efraín } \\
\text { Bámaca } \\
\text { Velásquez }\end{array}$} & $\begin{array}{l}\text { Resolución en cum- } \\
\text { plimiento sentencia } \\
\text { Corte } \text { IDH }^{1}\end{array}$ & $\begin{array}{l}\text { Declara nulidad sobreseimiento } \\
\text { y ordena reapertura causa }\end{array}$ \\
\hline G & $\mathrm{CC}$ & 25-ago-10 & & $\begin{array}{l}\text { Amparo de Julio } \\
\text { Roberto Alpírez }\end{array}$ & $\begin{array}{l}\text { Otorga amparo y deja sin efectos } \\
\text { resolución de la CSJ (desconoce } \\
\text { decisión de Corte IDH) }\end{array}$ \\
\hline$H$ & & & & \multirow{2}{*}{$\begin{array}{l}\text { Resolución en cumpli- } \\
\text { miento resoluciones } \\
\text { Corte IDH }\end{array}$} & $\begin{array}{l}\text { Declara nulidad sobreseimiento } \\
\text { y ordena reapertura causa }\end{array}$ \\
\hline H & CS) & & & & $\begin{array}{l}\text { Da intervención a Jennifer } \\
\text { Kristina Harbury }\end{array}$ \\
\hline
\end{tabular}

Fuente: Elaboración propia a partir de datos extraídos de las decisiones estudiadas.

Caso A - Decisión sobre Fuero Militar: el 3 de marzo de 1997 la CC adoptó una decisión que constituye un caso paradigmático de protección judicial de derechos humanos, al señalar que una norma que impide que en todos los casos los militares sean juzgados por tribunales castrenses se ajusta a la Constitución, ampliando, en una decisión de alcance general, las posibilidades de criminalización. ${ }^{13}$

Casos B y C - Proceso(s) Myrna Elizabeth Mack Chang: en el curso del proceso penal adelantado por el asesinato de la antropóloga Myrna Mack, la CSJ adoptó dos decisiones que constituyen casos paradigmáticos de protección judicial de los derechos humanos, al lograr la investigación y condena de los autores materiales e intelectuales de un crimen en el que se vio involucrado de forma directa el aparato represor del Estado.

13 En los expedientes Nos 1031-96 y 1155-96 la Corte resolvió declarar sin lugar la inconstitucionalidad general planteada en contra del Decreto № 41-96 del Congreso de la República, que determina que en los casos de delitos o faltas comunes, cometidos por militares, se aplicará el Código Procesal Penal y serán juzgados por tribunales ordinarios, restringiendo el fuero militar, que se mantiene para los delitos cometidos en servicio activo y en relación con el servicio. 
Caso B - Sentencia contra el autor material: la sentencia proferida el 9 de febrero de 1994 por la $\mathrm{CSJ}^{14}$ se considera un caso de protección judicial de los derechos humanos, pues por primera vez llegó a conocimiento de esta instancia un crimen que implicaba agentes del Estado en una grave violación a los derechos humanos y la Corte no solo ratificó la condena impuesta al autor material, sino que abrió paso a la criminalización de otros implicados.

Caso C - Sentencia contra los autores intelectuales: diez años después de que se ordenara seguir con la investigación contra los demás implicados, el proceso llegó de nuevo a la CSJ. Esta vez dos de los presuntos autores intelectuales habían sido absueltos en primera instancia y otro más en segunda, decisión esta última que revocó la Corte el 14 de enero de 2004, ${ }^{15}$ advirtiendo que el tribunal declaró libre de todo cargo al investigado "bajo pretexto de una contradicción inexistente" (CSJ, 2004: 9). Se trata de un caso de protección judicial de los derechos humanos, ya que criminaliza a quien dio la orden de ejecutar a Myrna Mack.

Caso D - Negación de extradiciones a España: en 1999 Rigoberta Menchú Tum presentó ante la Audiencia Nacional Española una querella para que se investigaran delitos ocurridos en Guatemala entre 1978 y $1986 .{ }^{16}$ En el curso del proceso la Audiencia Nacional libró órdenes de captura contra algunos de los involucrados, por lo que un tribunal de sentencia penal ordenó la detención provisional de las personas requeridas con fines de extradición, decisión contra la cual interpusieron amparo Ángel Aníbal Guevara Rodríguez y Pedro García Arredondo.

En primera instancia el tribunal de amparo resolvió negarlo, sin embargo, esta decisión fue apelada por Efraín Ríos Montt -en calidad de tercero interesado- y Guevara Rodríguez, y revocada por la CC el 12 de diciembre de $2007^{17}$ en un caso paradigmático de desprotección judicial de los derechos humanos. ${ }^{18}$

Caso E - Decisión desapariciones Choatalum: un caso paradigmático de protección judicial de derechos humanos por la CC es la sentencia del 7 de julio de 2009,19 que declaró que resulta acorde con la Constitución aplicar una norma que consagra la desaparición forzada y su carácter de delito "permanente en tanto no se libere a la víctima"

14 Casación N $\mathrm{N}^{\mathrm{o}}$ 3658-3688, Pieza 20. La Corte resolvió los recursos de casación interpuestos por Helen Beatriz Mack Chang y Noel de Jesús Beteta Álvarez, contra la sentencia de primera instancia, confirmada en segunda, donde se condenó a este último a la pena de 25 años de prisión por el asesinato de Myrna.

15 Casaciones Nos. 109-2003 y 110-2003.

16 Entre los que se encontraban el genocidio ocurrido durante el conflicto, el asalto a la Embajada de España, en el que fallecieron incineradas 37 personas - una de las cuales era su padre-, así como la muerte de sacerdotes españoles, delitos de los que serían presuntos responsables autoridades civiles y militares del país.

17 Expediente $\mathrm{N}^{\circ} 3380-2007$.

18 En este fallo la Corte desconoció la competencia del Reino de España para juzgar delitos de trascendencia internacional, mediante una retorcida interpretación, al dotar a los delitos investigados del carácter de conexos a delitos políticos, sobre la base de que se circunscriben a la época del conflicto armado.

19 Expediente $\mathrm{N}^{\circ}$ 929-2008. Apelación de incidente de inconstitucionalidad en caso concreto, interpuesta luego de que un tribunal de sentencia penal -con carácter de tribunal constitucional- resolvió en primera instancia negar la declaratoria solicitada por la defensa. 
(art. 201 del Código Penal), aun cuando la conducta investigada se hubiere iniciado con anterioridad a su expedición.

Casos F, G, H - Reapertura Proceso Bámaca: Efraín Bámaca Velásquez desapareció el 12 de marzo de 1992 después de un enfrentamiento entre el Ejército y la guerrilla. Las fuerzas armadas guatemaltecas lo apresaron vivo y "lo recluyeron secretamente en varias dependencias militares, donde lo torturaron y, eventualmente, lo ejecutaron" (Corte IDH, 2000: 5). En noviembre de 2000 la Corte IDH emitió sentencia en el caso Bámaca vs. Guatemala ordenando al Estado guatemalteco investigar los hechos, y desde diciembre de 2009 la CSJ y la CC han emitido una serie de decisiones que se contraponen sobre la reapertura del proceso.

Caso F - Cumplimiento Sentencia Corte IDH: a finales de 2009 el Ministerio Público solicitó a la Cámara Penal de la CSJ la ejecución de la sentencia de la Corte IDH, solicitud a la que accedió la CSJ el 11 de diciembre de $2009^{20}$ teniendo en cuenta que la instancia internacional había declarado el sobreseimiento como violatorio de los principios universales de justicia. Con esta decisión la CSJ dio lugar a la criminalización, por lo que se trata de un caso más de protección judicial de los derechos humanos.

Caso G - Amparo contra decisión de la CSJ: el excoronel del ejército Julio Roberto Alpírez impugnó con un amparo la decisión adoptada el 11 de diciembre de 2009 por la CSJ y el 25 de agosto de 2010 la CC accedió a sus peticiones, ${ }^{21}$ resolviendo dejar en suspenso la resolución de la CSJ. Dicho fallo restringe las posibilidades de criminalización, por lo que se trata de un caso de desprotección judicial de los derechos humanos.

Caso H - Cumplimiento Resoluciones Corte IDH: el 18 de noviembre de 2010 la Corte IDH se pronunció al revisar el cumplimiento del fallo. En cuanto a lo dispuesto por la CC, señaló que "la prevalencia de un sobreseimiento por encima de los derechos de las víctimas genera que el proceso continúe con manifiestas violaciones del acceso a la justicia, proyectando la impunidad en el tiempo y haciendo ilusorio lo ordenado por esta Corte" (Corte IDH, 2010: 20).

Luego de ello, previa solicitud de ejecución del fallo de la Corte IDH planteada tanto por el Ministerio Público como por Jennifer Kristina Harbury, viuda de Bámaca, el 18 de enero de 2011 la CSJ profirió nueva resolución disponiendo reabrir el proceso, ${ }^{22}$ ampliando con ello las posibilidades de criminalización, por lo que se trata de un caso de protección judicial de los derechos humanos.

Según informaciones de prensa, en febrero de 2011 la CC concedió amparo provisional a Julio Roberto Alpírez, lo que habría impedido de nuevo la reapertura del proceso. ${ }^{23}$

El Cuadro 6 reúne la información que el anterior recuento nos permite extraer sobre nuestra variable dependiente:

Expediente No MP001/2009/10170.

Expediente $\mathrm{N}^{\circ}$ 548-2010.

Y permitir la intervención de la viuda de Bámaca Velásquez en el trámite penal N ${ }^{\circ}$ C-603-1996.

El Periódico. Gladys Galeano. CC suspende de nuevo reapertura del caso Bámaca, 13 de febrero, 2011. 
Cuadro 6. Protección judicial de DD.HH. en los casos estudiados

\begin{tabular}{|c|c|c|c|c|}
\hline Caso & Asunto & Indicador & Dimensión & $\begin{array}{l}\text { Protege } \\
\text { DD.HH. }\end{array}$ \\
\hline A & Fuero & Restringe el fuero militar & $\begin{array}{l}\text { Amplía posibilidades de } \\
\text { criminalización }\end{array}$ & Sí \\
\hline B & Myrna Mack & $\begin{array}{l}\text { Confirma condena criminal y } \\
\text { ordena investigación criminal } \\
\text { contra otros involucrados }\end{array}$ & $\begin{array}{l}\text { Criminaliza y amplía posibili- } \\
\text { dades de criminalización }\end{array}$ & Sí \\
\hline $\mathrm{C}$ & & Revoca absolución y condena & Criminaliza & Sí \\
\hline $\mathrm{D}$ & J. Universal & $\begin{array}{l}\text { (-) Desconoce carácter de crimen } \\
\text { más grave, de trascendencia para } \\
\text { la comunidad internacional }\end{array}$ & $\begin{array}{l}\text { Restringe posibilidades de } \\
\text { criminalización }\end{array}$ & No \\
\hline E & Choatalum & $\begin{array}{l}\text { Restringe posibilidades de } \\
\text { prescripción }\end{array}$ & $\begin{array}{l}\text { Amplía posibilidades de } \\
\text { criminalización }\end{array}$ & Sí \\
\hline $\mathrm{F}$ & & Ordena reapertura causa & $\begin{array}{l}\text { Amplía posibilidades de } \\
\text { criminalización }\end{array}$ & Sí \\
\hline G & Bámaca & $\begin{array}{l}\text { (-) Deja sin efectos resolución que } \\
\text { ordena reapertura }\end{array}$ & $\begin{array}{l}\text { Restringe posibilidades de } \\
\text { criminalización }\end{array}$ & No \\
\hline $\mathrm{H}$ & & Ordena reapertura causa & $\begin{array}{l}\text { Amplía posibilidades de } \\
\text { criminalización }\end{array}$ & Sí \\
\hline
\end{tabular}

Fuente: Elaboración propia a partir de las decisiones estudiadas.

\section{ANÁLISIS EXPLICATIVO}

Según el diseño de investigación, la protección judicial de derechos humanos por parte de las altas Cortes guatemaltecas (y) es menos probable cuando hay políticos o altos mandos militares que formaron parte de los regímenes autoritarios involucrados en el caso $\left(\mathrm{x}^{1}\right)$, así como cuando los decisiones son proferidas por magistrados con mayor tradición política o familiares en política $\left(x^{3}\right)$, mientras es más probable cuando en el proceso intervienen terceros individuales u ONG reclamando la protección de los derechos $\left(\mathrm{x}^{2}\right)$, así como cuando hay decisiones adoptadas por Cortes internacionales que se han pronunciado sobre el mismo tema o asunto en defensa de los derechos humanos $\left(x^{4}\right)$.

Un análisis de presencia y ausencia de nuestras variables explicativas consideradas individualmente no nos permite corroborar las hipótesis planteadas, pues para cada una de ellas tenemos tanto casos positivos como negativos. Con todo, es posible que en presencia de múltiples variables independientes su combinación arroje una explicación. ${ }^{24}$

24 Fenómeno llamado por Charles Ragin "causalidad coyuntural", "dado que solo la articulación de múltiples factores en una coyuntura específica posibilita el resultado" (Pérez Liñán, 2007: 14). 
En busca de explorar sistemáticamente configuraciones causales complejas Charles Ragin ha desarrollado un protocolo comparativo, denominado Qualitative Comparative Analysis (QCA), que permite identificar configuraciones causales necesarias y suficientes (Pérez Liñán, 2007: 20). Una tabla como la contenida en el Cuadro 7 nos permite ver el comportamiento de nuestras variables en conjunto:

Cuadro 7. Presencia y ausencia de variables

\begin{tabular}{lllllll}
\hline & \multicolumn{1}{c}{ Caso } & \multicolumn{1}{c}{ Y } & \multicolumn{1}{c}{$\mathrm{x}^{1}$} & \multicolumn{1}{c}{$\mathrm{x}^{2}$} & \multicolumn{1}{c}{$\mathrm{x}^{3}$} & \multicolumn{1}{c}{$\mathrm{x}^{4}$} \\
\hline A & Fuero & Protección & Presiones & Sin Social Ac. & Sin Tray. Política. & Sin D. Previa \\
B & Myrna & Protección & Presiones & Social Ac. & Sin Tray. Política. & Sin D. Previa \\
C & Myrna & Protección & Presiones & Social Ac. & Tray. Política. & Dec. Previa \\
D & J. Universal & Desprotección & Presiones & Social Ac. & Tray. Política. & Sin D. Previa \\
E & D. Forzada & Protección & Sin presiones & Social Ac. & Tray. Política. & Dec. Previa \\
F & Bámaca & Protección & Enclaves $\left.{ }^{*}\right)$ & Sin Social Ac. & Tray. Política. & Dec. Previa \\
G & Bámaca & Desprotección & Enclaves $^{*}$ & Sin Social Ac. & Tray. Política. & Dec. Previa \\
H & Bámaca & Protección & Enclaves $\left.^{*}\right)$ & Social Ac. & Tray. Política. & Dec. Previa \\
\hline
\end{tabular}

Fuente: Elaboración propia.

(*) En estos casos están directamente vinculados altos mandos militares o políticos, pero no intervienen en el trámite de expedición de la decisión.

Lo anterior se puede simplificar en una matriz de datos, como la del Cuadro 8:

Cuadro 8. Matriz de datos

\begin{tabular}{|c|c|c|c|c|c|c|c|}
\hline \multicolumn{2}{|r|}{ Caso } & \multirow{2}{*}{$\frac{\text { Corte }}{\text { CC }}$} & \multirow{2}{*}{$\frac{Y}{1}$} & \multirow{2}{*}{$\frac{x^{1}}{1}$} & \multirow{2}{*}{$\frac{x^{2}}{0}$} & \multirow{2}{*}{$\frac{x^{3}}{0}$} & \multirow[t]{2}{*}{$x^{4}$} \\
\hline A & Fuero & & & & & & \\
\hline B & Myrna & CSJ & 1 & 1 & 1 & 0 & 0 \\
\hline C & Myrna & CSJ & 1 & 1 & 1 & 1 & 1 \\
\hline D & J. Univ. & $\mathrm{CC}$ & 0 & 1 & 1 & 1 & 0 \\
\hline E & D. Forzada & $\mathrm{CC}$ & 1 & 0 & 1 & 1 & 1 \\
\hline F & Bámaca & CSJ & 1 & 1 & 0 & 1 & 1 \\
\hline G & Bámaca & $\mathrm{CC}$ & 0 & 1 & 0 & 1 & 1 \\
\hline $\mathrm{H}$ & Bámaca & CSJ & 1 & 1 & 1 & 1 & 1 \\
\hline
\end{tabular}

Fuente: Elaboración propia.

Los resultados del análisis con el software arrojan como condiciones suficientes para la protección judicial de derechos humanos (y): la ausencia de politización en las Cortes $\left(\sim \mathrm{x}^{3}\right)$ y la presencia de social accountability en conjunción con decisiones previas de Cortes internacionales $\left(\mathrm{x}^{2 *} \mathrm{x}^{4}\right)$. 
Hay que advertir que tenemos solo ocho casos y que dos parejas de casos tienen las mismas condiciones $(\mathrm{C}+\mathrm{H}$ y $\mathrm{F}+\mathrm{G})$, lo que limita la diversidad de datos empíricos, sin embargo se analizan todos los casos sobre los que fue posible tener información y los resultados son coherentes no solo con las hipótesis planteadas, sino también con la literatura sobre el tema.

La primera configuración $\left(\sim \mathrm{X}^{3}\right)$ está presente en dos de los casos de protección judicial de derechos humanos (A y B), mientras la segunda $\left(\mathrm{x}^{2 *} \mathrm{x}^{4}\right)$ está en tres $(\mathrm{C}, \mathrm{E}, \mathrm{H})$, cubriendo cinco de los seis casos positivos. ${ }^{25} \mathrm{El}$ caso que queda por fuera de la explicación es el F, donde no hay social accountability pero intervino el Ministerio Público solicitando la reapertura del proceso.

Hay dos variables explicativas que el diseño de investigación no tuvo en cuenta, la primera es el tipo de Corte y la segunda, que aparece después de un estudio cualitativo de los casos, la podemos llamar "presiones proimpunidad de actores con vida política activa".

Aun cuando es posible prever que es menor la posibilidad de protección judicial de derechos humanos cuando los casos son conocidos por la CC, debido al carácter directo de su designación, el no tener casos de desprotección judicial de la CSJ impide corroborar empíricamente esta hipótesis. Sin embargo, esto explica la contradicción entre los casos F y $G$ que comparten condiciones, con diferentes resultados y que fueron fallados uno por la CC y otro por la CSJ.

En cuanto a las "presiones proimpunidad de actores con vida política activa", podemos explorar cómo se comportan las configuraciones causales si reducimos los casos positivos de $\left(x^{1}\right)$ a aquellos donde los militares o políticos implicados se mantienen activos en la vida política del país, esto es, en los casos D, F, G y H, donde están involucrados Ríos Montt y Pérez Molina.

Con esta modificación los resultados del análisis arrojan como condiciones suficientes para la protección judicial de derechos humanos (y): la presencia de social accountability en conjunción con decisiones previas de Cortes internacionales $\left(\mathrm{x}^{2 *} \mathrm{x}^{4}\right)$, la ausencia de politización en las Cortes $\left(\sim \mathrm{x}^{3}\right)$ y la ausencia de enclaves autoritarios $\left(\sim \mathrm{x}^{1}\right)$.

Como en el anterior análisis, la primera configuración $\left(\mathrm{x}^{2 *} \mathrm{x}^{4}\right)$ está en tres de nuestros casos de protección judicial de los derechos humanos $(\mathrm{C}, \mathrm{E}, \mathrm{H})$, la segunda $\left(\sim \mathrm{X}^{3}\right)$ está presente en dos $(\mathrm{A}$ y $\mathrm{B})$, mientras la tercera $\left(\sim \mathrm{x}^{1}\right)$ está solo en uno $(\mathrm{E})$, cubriendo así -de nuevo- cinco de nuestros seis casos positivos. ${ }^{26}$ La importancia menor de la configuración $\left(\sim \mathrm{X}^{1}\right)$ puede explicase por los dos casos en que, a pesar de estar presentes estos actores, la CSJ emite providencias en su contra.

El conjunto de resultados permite ver que si bien ninguna de las explicaciones previstas en las hipótesis planteadas es condición necesaria para la protección judicial de derechos humanos, sí son condiciones suficientes, ya por separado $\left(\sim \mathrm{x}^{1}\right)$ y $\left(\sim \mathrm{x}^{3}\right)$ o ya conjuntamente $\left(\mathrm{x}^{2 *} \mathrm{x}^{4}\right)$, constatando la influencia de cada una de ellas en el resultado esperado.

25 La cobertura de la solución es de 0,83 y la consistencia de 1,0.

26 Como en el anterior análisis, la cobertura de la solución es de 0,83 y la consistencia de 1,0. 
Es necesario llamar la atención sobre el hecho de que salvo el caso sobre el carácter permanente del delito de desaparición forzada (2009) que impide que se configure la prescripción y aquel que restringe el fuero militar (1997), las decisiones analizadas no introducen criterios jurisprudenciales aplicables a muchos otros casos.

\section{CONCLUSIONES}

Este trabajo parte de la idea de que el poder judicial puede influir en el proceso transicional años después de que las élites adoptaran decisiones que se suponían definitorias mediante la criminalización de violaciones a los derechos humanos. El objeto de investigación fue analizar la respuesta de las Altas Cortes guatemaltecas a los casos que han llegado hasta ellas y la pregunta que se pretendió responder es por qué en algunos de estos casos las Altas Cortes protegen los derechos humanos y en otros no.

Este fenómeno, que ha recibido más atención en el Cono Sur, merece ser estudiado en Centroamérica donde después de los Acuerdos de Paz se han hecho grandes esfuerzos para reforzar la independencia del poder judicial y contribuir a la efectividad del Estado de Derecho. Para ello se optó por iniciar por Guatemala, donde la Corte Suprema de Justicia y la Corte de Constitucionalidad han proferido resoluciones que resultan de interés para estudiar el rol del poder judicial en la defensa de los derechos humanos durante y después de la transición.

Del análisis de nuestros ocho casos -dos de desprotección judicial de derechos humanos y seis de protección-, es importante resaltar que los dos negativos los constituyen decisiones proferidas por la Corte de Constitucionalidad en trámites de amparo. Así pues el amparo, instituido para la defensa de derechos, ha servido en estos dos casos específicos para burlar el orden internacional de protección de los mismos. Ello no quiere decir que se desconozca la importancia general del recurso de amparo para la protección de derechos, se trata simplemente de advertir cómo en estos dos casos la encargada de asegurar el orden constitucional se vio influida por presiones que afectaron sus decisiones.

Por su parte, el análisis de configuraciones causales corrobora la hipótesis sobre el impacto negativo de las trayectorias o vínculos políticos de los magistrados en el resultado esperado, mientras muestra el impacto positivo de la conjunción de social accountability con decisiones previas de Cortes internacionales. Las presiones proimpunidad solo aparecen en las configuraciones causales cuando se reducen los casos a aquellos en que los actores que presionan tienen vida política activa.

Si se comparan solo los casos positivos y negativos fallados por la Corte de Constitucionalidad es posible ver cómo en los negativos las decisiones además de proferirse en trámites de amparo, involucran personajes notorios del período autoritario y que se mantienen activos en la vida política del país, variable que no afecta negativamente las decisiones de la Corte Suprema.

Así pues, es posible concluir que en los casos en estudio las presiones proimpunidad fueron capaces de doblegar a la Corte de Constitucionalidad que profirió decisiones 
indefendibles desde el punto de vista jurídico incluso en presencia de social accountability o precedentes judiciales de orden internacional, mientras la Corte Suprema se mantuvo inmune a dichas presiones, aun cuando sus magistrados cada vez más tienen trayectorias políticas.

La Constitución que antecedió la transición en Guatemala establece un marco institucional propicio para la defensa judicial de los derechos humanos al reconocer la preeminencia de las normas que los consagran y declarar el principio de independencia judicial, tanto desde el plano funcional como desde el presupuestal, pero al mismo tiempo los mecanismos de selección que señala para los magistrados -sobre todo los de la Corte de Constitucionalidad, designados de forma directa- y los períodos tan cortos de designación, menguan la declarada independencia.

En cualquier caso hay que llamar la atención también sobre la importancia de los casos de protección judicial de los derechos humanos que se estudiaron, tales como las decisiones sobre fuero militar o el carácter permanente del delito de desaparición forzada que sientan precedentes judiciales de gran importancia para la incorporación de estándares internacionales de protección de los derechos humanos al derecho interno guatemalteco.

Este trabajo se ocupa de una mínima parte de los temas que deben ser explorados, quedando pendiente indagar lo que ha pasado en otros países de la región, el peso de nuestras variables explicativas en otros contextos y en otras etapas del proceso, las razones del rezago en la judicialización de estos casos y las posibilidades de impulsarlos.

\section{REFERENCIAS}

Alcántara, Manuel; Paramio, Ludolfo; Freidenberg, Flavia y Déniz, José. 2006. Reformas económicas y consolidación democrática en América Latina. Vol. 6. Madrid: Síntesis.

Alcántara Manuel y Freidenberg, Flavia. 2006. "El proceso político en perspectiva comparada". En Reformas económicas y consolidación democrática en América Latina. Vol. 6, editado por M. Alcántara, L. Paramio, F. Freidenberg y J. Déniz, 85-150. Madrid: Síntesis.

Barahona de Brito, Alexandra; Aguilar Fernández, Paloma; Gonzales Enríquez, Carmen. 2002. Las políticas hacia el pasado. Juicios, depuraciones, perdón y olvido en las nuevas democracias. Madrid: Ediciones Istmo.

Bethell, Leslie. 1997. Historia de América Latina. Vol. 12. Política y sociedad desde 1930. Barcelona: Cambridge University Press Crítica.

Booth Walling, Carrie y Sikkink, Kathryn. 2008. "La cascada de justicia y el impacto de los juicios de derechos humanos en América Latina". Cuadernos del CLAEH 96-97: 15-40.

Carbonell, Miguel; Fix-Fierro, Héctor y Vázquez, Rodolfo. 2004. Jueces y Derecho. México: Porrúa-UNAM.

Collins, Cath. 2010. Post-transitional Justice. Human Rights Trials in Chile and El Salvador. Pennsylvania: Editorial Penn State Press.

Collins, Cath. 2006. "Grounding Global Justice: International Networks and Domestic Human Rights Accountability in Chile and El Salvador". Journal of Latin American Studies 38 (4): 711-738.

Courtis, Cristian. 2004. "Reyes desnudos. Algunos ejes de caracterización de la actividad política de los tribunales". En Jueces y Derecho, compilado por M. Carbonell, H. Fix-Fierro y R. Vázquez, 389-417. México: Porrúa-UNAM. 
Courtis, Cristian. 2005. "Breves apuntes de caracterización de la actividad política de los tribunales". En Jueces y Política, editado por F. Ojesto, J. Orozco Henríquez y R. Vázquez, 59-84. México: Editorial Porrúa.

Dahl, Robert A. 2000. La democracia y sus críticos. Barcelona: Paidós.

Domingo, Pilar. 2004. "Judicialization of Politic or Politicization of the Judiciary? Recent Trends in Latin America". Democratization 11 (1): 104-126.

Dworkin, Ronald. 1977. Taking Rights Seriously. Cambridge: Harvard University Press.

Elster, Jon. 1995. "On Doing what One Can: An Argument against Post-communist Restitution and Retribution". En Transitional Justice: How Emerging Democracies Reckon with Former Regimes, editado por N. Kritz, 566-568. Washington D.C.: United States Institute of Peace Press.

Epstein, Lee; Knight, Jack y Martin Andrew D. 2001. "The Supreme Court as a Strategic National Policymaker". Emory Law Journal 50: 583-611.

Epstein, Lee; Knight, Jack y Shvetsova, Olga. 2000. "The Role of Constitutional Courts in the Establishment and Maintenance of Democratic Systems of Government". Paper presented at the annual meeting of the American Political Science Association. Washington D.C.

Hart, H.L.A. 1992. El concepto de derecho. Buenos Aires: Abeledo-Perrot.

Helmke, Gretchen y Sanders, Mitchell S. 2006. "Modeling Motivations: A Method for Inferring Judicial Goals from Behavior". The Journal of Politics 68 (4): 867-878.

Kapiszewski, Diana. 2009. “Tactical balancing and Prioritizing Pragmatism: High Court Decision-making on Economic Policy Cases in Brazil". Paper prepared for delivery at the conference Judicial Politics in Latin America. México D.F.: CIDE, March 4-8.

Kapiszewski, Diana; Taylor, Matthew. 2008. "Doing Courts Justice? Studying Judicial Politics in Latin America". Perspectives on Politics 6 (4): 741-767.

Karl, Terry Lynn. 1990. "Dilemmas of Democratization in Latin America". Comparative Politics 23 (1): 1-21.

Keck, Margaret E. y Sikkink, Kathryn. 1998. Activist beyond Borders: Advocacy Networks in International Politics. Ithaca y Londres: Cornell University Press.

Kennedy, Duncan. 1997. A Critique of Adjudication. Cambridge: Harvard University Press.

Knight, Jack y Epstein, Lee. 1996. "On the struggle for Judicial Supremacy". Law and Society Review 30 (1): 87-120.

Knight, Jack y Epstein, Lee. 1996. "The Norm of Stare Decisis". American Journal of Political Science 40 (4): 1019-1935.

Kritz, Niel J. 1995. Transitional Justice: How Emerging Democracies Reckon with Former Regimes. Washington D.C.: United States Institute of Peace Press.

Leonardo Segura, Mónica. 2010. "Guatemala". Las víctimas y la justicia transicional ¿Están cumpliendo los Estados latinoamericanos con los estándares internacionales? Washington D.C.: Fundación para el Debido Proceso Legal.

Linares, Sebastián. 2008. La ilegitimidad democrática del control judicial de las leyes. Madrid: Editorial Marcial Pons.

Maravall, José María. 2008. La confrontación política. Madrid: Taurus.

Maravall, José María. 2003. "The Rule of Law as a Political Weapon". En Democracy and the Rule of Law, J.M. Maravall y A. Przeworski, 261-301. Cambridge: Cambridge University Press.

Maravall, José María y Przeworski, Adam. 2003. Democracy and the Rule of Law. Cambridge: Cambridge University Press.

Martínez Barahona, Elena. 2009. Seeking the Political Role of the third government branch. A comparative approach to High Courts in Central America. Liepzig: VDM Verlag Dr. Müller.

McAdams, James. 1997. Transitional Justice and the Rule of Law in New Democracies. London: University of Notre Dame Press.

O'Donnell, Guillermo; Schmitter, Phillipe. 1986. Transiciones desde un gobierno autoritario. Conclusiones tentativas sobre las democracias inciertas, Vol. 4. Buenos Aires: Paidós.

O'Donnell, Guillermo. 2007. Disonancias. Críticas democráticas a la democracia. Buenos Aires: Prometeo Libros. 
Ojesto, Fernando; Orozco Henríquez, Jesús y Vázquez, Rodolfo. 2005. Jueces y Política. México: Editorial Porrúa.

Osiel, Mark. 2005. "Respuestas estatales a las atrocidades masivas". En Entre el Perdón y el Paredón, editado por A. Rettberg, 67-80. Bogotá: Universidad de los Andes.

Pásara, Luis. 2010. Ley, justicia y sociedad en América Latina. México: Instituto de Investigaciones Jurídicas Universidad Nacional Autónoma de México.

Pérez Liñán, Aníbal. 2007. El método comparativo: Fundamentos y desarrollos recientes. Documento de trabajo sin publicar, versión 1.2.

Peruzzotti, Enrique y Smulovitz, Catalina. 2006. Enforcing the rule of law: social accountability in the new Latin American democracies. Pittsburgh: University of Pittsburgh Press.

Peruzzotti, Enrique y Smulovitz, Catalina. 2002. Controlando la politica. Ciudadanos y Medios en las Nuevas Democracias Latinoamericanas. Buenos Aires: Editorial Temas.

Rettberg, Angelika. 2005. Entre el perdón y el paredón. Bogotá: Universidad de los Andes.

Risse, Thomas; C. Roop, Stephen y Sikkink, Kathryn. 1999. The Power of Human Rights. International Norms and Domestic Change. New York: Cambridge University Press.

Risse, Thomas y Sikkink, Kathryn. 1999. "The Socialization of International Human Rights Norms in to Domestic Practices: Introduction" En The Power of Human Rights. International Norms and Domestic Change, editado por T. Risse, C. Roop, y K. Sikkink, 1-38. New York: Cambridge University Press.

Roht-Arriaza, Naomi. 2002. "El papel de los actores internacionales en los procesos nacionales de responsabilidad". En Las políticas hacia el pasado. Juicios, depuraciones, perdón y olvido en las nuevas democracias, editado por A. Barahona de Brito, et al., 71-101 Madrid: Ediciones Istmo.

Roop, Stephen; Sikkink, Kathryn. 1999. "International Norms and Domestic Politics in Chile and Guatemala" En The Power of Human Rights. International Norms and Domestic Change, editado por T. Risse, C. Roop, y K. Sikkink, 172-204. New York: Cambridge University Press.

Rouquié, Alain. 1997. "Los militares en la política latinoamericana desde 1930". En Historia de América Latina, editado por L. Bethell, 281-341. Barcelona: Cambridge University Press Crítica.

Sieder, Rachel. 2002. "Políticas de Guerra, Paz y Memoria en América Central". En Las políticas hacia el pasado. Juicios, depuraciones, perdón y olvido en las nuevas democracias, editado por A. Barahona de Brito et al., 247-284. Madrid: Ediciones Istmo.

Skaar, Elin. 2011. Judicial Independence and Human Rights in Latin America: Violations, Politics, and Prosecution. New York: Palgrave Macmillan.

Sommer, Ehud N. y Sekercioglu, M. Eser. 2007. "Institutional antecedents of strategic judicial decision-making". Paper presented at the Midwest Political Science Association Annual Meeting. Chicago.

Uprimny, Rodrigo. 2007. "La judicialización de la política en Colombia: casos, potencialidades y riesgos". Revista Sur Internacional de Derechos Humanos 6: 52-69.

Uprimny, Rodrigo y Guzmán, Diana Esther. 2007. "Experiencias exitosas de lucha contra la impunidad". Versión escrita de la charla realizada por Rodrigo Uprimny en Santo Domingo en la Conferencia de la SIP. DeJusticia.

Valencia Villa, Hernando. 2007. "Introducción a la justicia transicional". Conferencia magistral impartida en la cátedra Latinoamericana "Julio Cortázar" de la Universidad de Guadalajara, México, 26 de octubre de 2007. Publicada en Claves de Razón Práctica 180: 76-82.

Walzer, Michael. 2010. Pensar políticamente. Barcelona: Paidós.

\section{Sentencias:}

Corte de Constitucionalidad. Exp. 1031-96 y 115596. Sentencia del 3 de marzo de 1997. Inconstitucionalidad General. Caso Fuero Militar. En: http:/ / www.cc.gob.gt/ (acceso, 19 de febrero de 2011). 
Corte de Constitucionalidad. Exp. 3380-2007. Sentencia del 12 de diciembre de 2007. Amparo en caso Extradición Ríos Montt y otros. En: http:/ / www.cc.gob.gt/ (acceso, 16 de febrero de 2011).

Corte de Constitucionalidad. Exp. 929-2008. Sentencia del 7 de julio de 2009. Incidente de inconstitucionalidad en caso concreto, propuesto por Felipe Cusanero Coj. En: http://www.cc.gob.gt/ (acceso, 16 de febrero de 2011).

Corte de Constitucionalidad. Exp. 548-2010. Sentencia del 25 de agosto de 2010. Amparo en caso Bámaca, propuesto por Julio Roberto Alpírez.

Corte Interamericana de Derechos Humanos, Sentencia del 25 de noviembre de 2000. Caso Bámaca vs. Guatemala. En: http:/ / www.corteidh.or.cr (acceso, 18 de febrero de 2011).

Corte Interamericana de Derechos Humanos, Sentencia del 25 de noviembre de 2003. Caso Myrna Mack vs. Guatemala. En: http:/ / www.corteidh.or.cr (acceso, 18 de febrero de 2011).

Corte Interamericana de Derechos Humanos, Resolución del 16 de noviembre de 2009. Caso Myrna Mack vs. Guatemala. En: http:/ / www.corteidh.or.cr (acceso, 18 de febrero de 2011).

Corte Interamericana de Derechos Humanos, Resolución del 18 de noviembre de 2010. Caso Bámaca vs. Guatemala. Supervisión de Cumplimiento de Sentencia En: http:/ / www.corteidh.or.cr (acceso, 18 de febrero de 2011).

Corte Suprema de Justicia. Pieza 20: 3658-3688. Sentencia del 9 de febrero de 1994, Casación en el Caso Myrna Mack. En: http:/ / www.myrnamack.org.gt (acceso, 12 de febrero de 2011).

Corte Suprema de Justicia. Recursos de casación conexados 109-2003 y 110-2003. Sentencia del 14 de enero de 2004. Caso Myrna Mack. En: http:/ / www.myrnamack.org.gt (acceso, 12 de febrero de 2011).

Corte Suprema de Justicia. Solicitud de ejecución de sentencia Corte Interamericana de Derechos Humanos. No MP001/2009/10170. Resolución de 11 de diciembre de 2009. Caso Bámaca.

Corte Suprema de Justicia. Solicitud de ejecución de sentencia Corte Interamericana de Derechos Humanos. Solicitud ejecución sentencia N ${ }^{\circ}$ MP001/2009/10170. Resolución de 21 de septiembre de 2010. Cumplimiento de Amparo, Caso Bámaca.

Corte Suprema de Justicia. Solicitud de ejecución de sentencia Corte Interamericana de Derechos Humanos. Proceso penal $\mathrm{N}^{\circ} \mathrm{C}-603-1996$. Resolución de 18 de enero de 2011. Caso Bámaca.

Tribunal Constitucional de España. STC 237/2005. Sentencia de 26 de septiembre de 2005. Caso Jurisdicción Universal España-Guatemala. En: http:/ / www.tribunalconstitucional.es (acceso, 8 de mayo de 2011).

\section{Informes y otros documentos:}

Amnistía Internacional. 2008. Guatemala: la denegación de las extradiciones solicitadas por España por crímenes de derecho internacional. En: http:/ / amnesty.org (acceso, 11 de abril de 2011).

Amnistía Internacional. 2002. El legado mortal de Guatemala. El pasado impune y las nuevas violaciones de derechos humanos. En: http://www2.amnistiainternacional.org/publica/ISBN_8486874785.html (acceso, 11 de mayo de 2011).

Comisión de Esclarecimiento Histórico. 1999. "Denegación de justicia". Guatemala, memoria del silencio. En Pásara y Wagner, 2000.

Comisión de Fortalecimiento de la Justicia. 1998. Una nueva justicia para la paz. Guatemala: Magna Terra Editores.

Comisión Internacional de Juristas. 2006. (CIJ). Análisis de la Iniciativa de Reforma de la Justicia Militar en Guatemala. En http:/ / www.icj.org (acceso, 11 de abril de 2011).

Instituto Interuniversitario de Iberoamérica. 2005. Perfil de Gobernabilidad de Guatemala. Red Eurolatinoamericana de Gobernabilidad para el Desarrollo (REDGOB). Salamanca: Ediciones Universidad de Salamanca.

Proyecto de Recuperación de la Memoria Histórica (REMHI). 1998. Guatemala, Nunca Más. En: http:// www.fundacionpdh.org/lesahumanidad/informes/guatemala (acceso, 11 de abril de 2011). 


\section{Prensa online:}

El Periódico. Kenia Reyes. Roxana Baldetti: "El caso Bámaca ya fue juzgado", 29 de marzo, 2010. En: http:/ / elperiodico.com.gt/es/20100329/pais/143971 (acceso, 07 de junio de 2011).

El Periódico. Claudia Palma. Otto Pérez: Gobierno influye a CSJ en caso Bámaca, 31 de enero, 2011. En: http:/ / www.elperiodico.com.gt/es/20110131/pais/189952 (acceso, 07 de junio de 2011).

El Periódico. Gladys Galeano. CC suspende de nuevo reapertura del caso Bámaca, 13 de febrero, 2011. En: http: / / www.elperiodico.com.gt/es/20110213/pais/190742/ (acceso, 07 de junio de 2011).

Prensalibre.com. Justicia. Confirman sentencia a Cusanero Coj por desaparición forzada. 17 de febrero, 2011. En: http://www.prensalibre.com/noticias/justicia/Confirman-sentencia-Cusanero-Cojdesaparicion_0_428957365.html (acceso, 07 de junio de 2011).

Siglo21.com. Manuel Hernández. Harbury está aquí para declarar en caso Bámaca, 25 de marzo, 2010. En: http:/ /www.s21.com.gt/nacionales/2010/03/25/harbury-esta-aqui-para-declarar-en-caso-bamaca (acceso, 07 de junio de 2011).

Siglo21.com. Confirma fallo contra ex militar, 17 de febrero, 2011. En: http:/ / www.s21.com.gt/breves/2011/02/17/ confirma-fallo-contra-ex-militar (acceso, 07 de junio de 2011).

\section{ANEXO I. INFORMACIÓN SOBRE MAGISTRADOS}

Cuadro 1. Magistrados que suscriben las decisiones de la Corte Constitucional

\begin{tabular}{|c|c|c|c|c|}
\hline Caso & a & d & e & g \\
\hline Luis Felipe Sáenz Juárez & Fuero & & & \\
\hline Rubén Homero López Mijangos & Fuero & & & \\
\hline José Arturo Sierra González & Fuero & & & \\
\hline Conchita Mazariegos Tobías & Fuero & & & \\
\hline Amado González Benítez- & Fuero & & & \\
\hline Mario Pérez Guerra & & Justicia Univ. & Desap. F. & Bámaca \\
\hline Gladys Chacón Corado* & & Justicia Univ. & Desap. F. & \\
\hline Roberto Molina Barreto & & Justicia Univ. & Desap. F. & Bámaca \\
\hline Alejandro Maldonado Aguirre* & & Justicia Univ. & Desap. F. & Bámaca \\
\hline José Rolando Quesada Fernández ${ }^{-}$ & Fuero & Justicia Univ. & & \\
\hline Juan Francisco Flores Juárez & Fuero & & Desap. F. & Bámaca \\
\hline Vinicio Rafael Garcia Pimentel- & & & & Bámaca \\
\hline
\end{tabular}

Fuente: Elaboración propia.

- Magistrados para los que no fue posible obtener datos.

* Magistrados con trayectoria política previa o familiares en política. 
Cuadro 2. Magistrados que suscriben las decisiones de la Corte Suprema de Justicia, Cámara Penal

\begin{tabular}{lcccc}
\hline \multicolumn{1}{c}{ Caso } & \multicolumn{1}{c}{$\mathrm{b}$} & $\mathrm{c}$ & $\mathrm{f}$ & $\mathrm{h}$ \\
\hline Juan José Rodill Peralta- & $\begin{array}{l}\text { Myrna 94 } \\
\text { Myrna 94 }\end{array}$ & & & \\
- & $\begin{array}{l}\text { Myrna 94 } \\
\text { Myrna 94 }\end{array}$ & & & \\
- & Myrna 94 & & & \\
- & & Myrna 04 & & \\
Justo Pérez Vásquez & Myrna 04 & & \\
$\begin{array}{l}\text { Napoleón Gutiérrez V. } \\
\text { Héctor Aníbal De León V. }\end{array}$ & & Myrna 04 & & \\
$\begin{array}{l}\text { Marieliz Lucero SibleyVR } \\
\text { Hilario Roderico Pineda S.* }\end{array}$ & & Myrna 04 & & \\
$\begin{array}{l}\text { Gustavo Adolfo M. } \\
\text { Héctor Manfredo M.* }\end{array}$ & & & Bámaca 09 & Bámaca 11 \\
$\begin{array}{l}\text { Gustavo Bonilla } \\
\text { Luis Arturo Archila } \\
\text { Cesar Ricardo Crisóstomo* }\end{array}$ & & & Bámaca 09 & Bámaca 11 \\
\hline
\end{tabular}

Fuente: elaboración propia.

- Magistrados para los que no fue posible obtener datos.

* Magistrados con trayectoria política previa o familiares en política.

VR Voto Razonado.

Cuadro 3. Trayectorias y observaciones

\begin{tabular}{|c|c|c|}
\hline Magistrado & Período & Observación \\
\hline Luis Felipe Sáenz Juárez & 1996-2001 & $\begin{array}{l}\text { Doctor en Derecho Magistrado Tribunal, Electoral Docente. } \\
\text { Libre ejercicio de la profesión. }\end{array}$ \\
\hline Rubén Homero López Mijangos & 1996-2001 & Profesor Universitario. \\
\hline José Arturo Sierra González & 1996-2001 & $\begin{array}{l}\text { Profesor Universitario. Juez de primera instancia. Candidato } \\
\text { CSJ } 2004 \text { y 2009. Magistrado CSJ 2009-2014, Cámara de } \\
\text { Amparo y Antejuicio. }\end{array}$ \\
\hline Conchita Mazariegos Tobías & 1996-2001 & $\begin{array}{l}\text { Magistrada Sala de Trabajo. Agente Especial del Ministerio } \\
\text { Público. Diputada al Congreso de la Republica 2004-2008 } \\
\text { (con posterioridad a la decisión estudiada). }\end{array}$ \\
\hline Amado González Benítez & 1996-2001 & Sin datos. \\
\hline José Rolando Quesada Fernández & $\begin{array}{l}1996-2001 \\
2006-2011\end{array}$ & Sin datos. \\
\hline Juan Francisco Flores Juárez & $\begin{array}{l}1996-2001 \\
2001-2005 \\
2006-2011\end{array}$ & $\begin{array}{l}\text { Sub-Procurador General de la Nación 1999-2001. Profesor } \\
\text { Universitario (Martínez Barahona, 2010). }\end{array}$ \\
\hline Juan José Rodill Peralta & X & Sin datos. \\
\hline Justo Pérez Vásquez & $x$ & Sin datos. \\
\hline Napoleón Gutiérrez Vargas & $2000-2004$ & $\begin{array}{l}\text { Auxiliar judicial. Juez de paz. Juez de instancia. Magistrado } \\
\text { Corte de Apelaciones. }\end{array}$ \\
\hline
\end{tabular}


Continuación Cuadro 3

\begin{tabular}{lcl}
\hline \multicolumn{1}{c}{ Magistrado } & Período & \multicolumn{1}{c}{ Observación } \\
\hline Héctor Aníbal De León Velasco & $2000-2004$ & $\begin{array}{l}\text { Juez Penal (Martínez Barahona, 2010). } \\
\text { Juez de primera instancia. Magistrada Corte de Apelaciones. }\end{array}$ \\
Marieliz Lucero Sibley & $2000-2004$ & $\begin{array}{l}\text { Con voto razonado en la sentencia de Myrna, donde se } \\
\text { aparta de la condena. }\end{array}$
\end{tabular}

Hilario Roderico Pineda Sánchez

Mario Pérez Guerra

Gladys Chacón Corado

Roberto Molina Barreto

Alejandro Maldonado Aguirre

Cesar Ricardo Crisóstomo

Barrientos Pellecer

Vinicio Rafael Garcia Pimentel

Gustavo Adolfo Mendizábal

Mazariegos

Héctor Manfredo Maldonado Méndez

Dimas Gustavo Bonilla

2009-2014

Luis Arturo Archila
Cargos en diferentes Ministerios 1986-1989. Cónsul en

Panamá 1991-1992. Integrante de la Comisión Asesora de Derechos Humanos de la Presidencia de la República 1988-1991 (Época del asesinato de Myrna). Magistrado CC 2006-2011 (Congreso de la R.). La CICIG lo señaló de tener vínculos con los presuntos autores intelectuales de Rodrigo Rosenberg.

2006-2011 Profesor Universitario (Martínez Barahona, 2010).

Litigante. Asesora jurídica de la municipalidad de Guatemala 1978-1986. Profesora Universitaria. Organismo de adminis2006-2011 tración judicial. Su hermano fue elegido magistrado de la CC para el período 2011-2016(Usac) y ella decidió impugnación sobre su designación.

2006-2011 Ejercicio libre de la profesión. Funcionario judicial. Procurador 2011-2016 General de la Nación 2005-2006 (Martínez Barahona, 2010).

1986-1991 Concejal. Diputado 1966-1970. Ministro 1970-1974. Embajador 2006-2011 1974-1980. Candidato presidencial 1982 (Antes del golpe 2011-2016 de Ríos Montt). Constituyente 1985. Embajador 1991-1996. Diputado 2004-2006.

Consultor USAID, PNUD, OEA. Director programas modernización judicial. Profesor universitario. Magistrado Sala de Apelaciones. Libre ejercicio de la profesión. Señalado por el PP como el instrumento de la UNE para perjudicar al precandidato presidencial Otto Pérez Molina. Hermano del alcalde de Quetzaltenango, electo por la GANA.

2006-2011 Sin datos sobre trayectoria previa. Aspirante a Fiscal 2010-2014

2009-2014 Fiscal del Ministerio Público. Profesor universitario. Magistrado Corte de apelaciones.

Asesor jurídico de municipios. Profesor universitario. La

2009-2014 Comisión Internacional de Juristas (CIJ) denunció ante el Congreso que perteneció a las fuerzas de seguridad del Estado en la década del 80.

Ejercicio libre de la profesión. Magistrado Corte de apelaciones. Profesor universitario. En septiembre de 2009 la CICIG recomendó formalmente al Congreso que no fuera electo magistrado. En comunicado de prensa de 2009 Naciones Unidas denunció la falta de transparencia en el proceso de elección de magistrados de la CSJ.

2009-2014 Magistrado suplente del Tribunal Supremo Electoral. Ejercicio libre de la profesión. Docente universitario.

Fuente: Elaboración propia, a partir de datos sobre las trayectorias de cada uno de los magistrados en la red, en la página del organismo judicial (http: / / www.oj.gob.gt), de la Corte de Constitucionalidad (http:/ / www.cc.gob.gt), así como en el trabajo de Martínez Barahona (2010) y reportes de prensa.

Martha Liliana Gutiérrez Salazar es candidata a doctor en ciencia política y master en estudios latinoamericanos por la Universidad de Salamanca, abogada de la Universidad de Caldas y especialista en derecho penal de la Universidad Nacional de Colombia.

E-mail: gutierrezsalazar@usal.es 